possibility of short term hypoxaemia lasting up to 30 minutes after physiotherapy. ${ }^{28-36}$ Most patients tolerate this hypoxia, but postural drainage, percussion, and vibration must be employed with particular care in critically ill patients ${ }^{29.31}$ and in those with low blood concentrations of oxygen. ${ }^{28}{ }^{30-32}$

Thus because of the risk of causing either bronchospasm or short term hypoxaemia postural drainage, percussion, and vibration should be used only in patients in whom its value has been proved. The forced expiration technique combined with postural drainage should be strongly considered as an alternative.

Senior Registrar,

D S SELSBY

Department of Anaesthesia,

General Infirmary,

Leeds LS1 3EX

1 Palmer KNV, Sellick BA. The prevention of postoperative pulmonary atelectasis. Lancet $1953 ; i: 164-8$

2 MacMahon C. Breathing and physical exercises for use in cases of wounds in the pleura, lung and diaphragm. Lancet 1915;ii: 769-70.

Demers R. Contraindications for chest physiotherapy. Chest 1986;89:962-3.

4 Anonymous. Chest physiotherapy under scrutiny [Editorial]. Lancet 1978;ii:1241.

4 Anonymous. Chest physiotherapy under scrutiny [Editorial]. Lancet 1978;i:

6 Petty TL, Jones NL, Mellins RB. Proceedings of the conference on the scientific basis of respiratory therapy. Am Rev Respir Dis 1974;110:129-42.

Lyle CB, Bianchi RF, Harris JH. Evaluation of respiratory physical therapy. N Engl f Med 1979;301:665

8 Sutton PP, Pavia D, Bateman JRM, Clarke SW. Chest physiotherapy: a review. Eur f Respir Dis 1982;63:188-201.

Kirrilof LH, Gregory RO, Rogers RM, Mazzocco MC. Does chest physical therapy work? Chest 1985;88:436-44.

10 Cochrane GM, Webber BA, Clarke SW. Effects of sputum on pulmonary function. Br Med 7 1977;ii:1181-3.

11 Tecklin JS, Holsclaw DS. Evaluation of bronchial drainage in patients with cystic fibrosis. Phys Ther 1975;55:1081-4.

12 Bateman JRM, Newman SP, Daunt KM, Pavia D, Clarke SW. Regional lung clearance of excessive lung secretions during chest physiotherapy in patients with stable chronic airways obstruction. Lancet 1979;i:294-7.
13 May DB, Munt PW. Physiologic effects of chest percussion and postural drainage in patients with stable chronic bronchitis. Chest 1979;75:29-32

14 Anthonisen $P$, Riis $P$. The value of lung physiotherapy in the treatment of acute exacerbations in chronic bronchitis. Acta Med Scand 1964;175:715-9.

15 Newton DAG, Stephenson A. Effect of physiotherapy on pulmonary function. Lancet 1978;i:228-9. 16 Campbell AH, O'Connell JM, Wilson F. The effect of chest physiotherapy on the FEV 1 in chronic bronchitis. Med $\mathcal{F}$ A ust 1975;i:33-5.

17 Wollmer P, Ursing K, Midgren B, Eriksson L. Inefficiency of chest percussion in the therapy of chronic bronchitis. Eur f Respir Dis 1985;66:233-9.

18 Graham WGB, Bradley DA. Efficiency of chest physiotherapy and intermittent positive pressure breathing in the resolution of pneumonia. $N$ Engl f Med 1978;299:624-7.

19 Britton S, Bejstedt M, Vedin L. Chest physiotherapy in primary pneumonia. Br Med $\mathcal{J}$ 1985;290:1703-4

20 Marini JJ, Pierson DJ, Hudson LD. Acute lobar atelectasis: a prospective comparison of fiberoptic bronchoscopy and respiratory therapy. Am Rev Respir Dis 1979;119:971-8.

21 DeBoeck C, Zinman R. Cough versus chest physiotherapy. Am Rev Respir Dis 1984;129:182-4.

22 Bateman JRM, Newman SP, Daunt KM, Sheahan NF, Pavia D, Clarke SW. Is cough as effective as chest physiotherapy in the removal of excessive tracheobronchial secretions? Thorax 1981;36:683-7.

23 Oldenberg JR, Dolovich MB, Montgomery JM, Newhouse MT. Effects of postural drainage, exercise, and cough on mucous clearance in chronic bronchitis. Am Rev Respir Dis 1979;120: $739-45$

24 Smalldone GC, Itoh H, Swift DL, Wagner HN. Effect of flow-limiting segments and cough on particle deposition and mucociliary clearance in the lung. Am Rev Respir Dis 1979:120:747-58.

25 Sutton PP, Parker RA, Webber BA. Assessment of the forced expiration technique, postural drainage and directed coughing in chest physiotherapy. Eur f Respir Dis 1983;64:62-8.

26 Sutton PP, Lopez-Vidriero MT, Pavia D. Assessment of percussion, vibratory-shaking and breathing exercises in chest physiotherapy. Am Rev Respir Dis 1985;66:147-52.

27 Pryor JA, Webber BA, Hodson ME, Baten JC. Evaluation of the forced expiration technique as an adjunct to postural drainage in the treatment of cystic fibrosis. Br Med f 1979;ii:417-8.

28 Gormezano J, Branthwaite MA. Pulmonary physiotherapy with assisted ventilation. Anaesthesia 1972;27:249-57.

29 Connors AF, Hammon WE, Martin RJ, Rogers RM. Chest physical therapy: the immediate effect on oxygenation in acutely ill patients. Chest 1980;78:559-64.

30 Huseby J, Hudson L, Stark K, Tyler M. Oxygenation during chest physiotherapy. Chest 1976;70:430.

31 Tyler $M$, Hudson L, Grose B, Huseby J. Prediction of oxygenation during chest physical therapy. Am Rev Respir Dis 1980;121(suppl):218.

32 McDonnell T, McNicholas WT, Fitzgerald MX. Hypoxaemia during chest physiotherapy in patients with cystic fibrosis. Ir f Med Sci 1986;155:345-8

33 Gormezano J, Branthwaite MA. Effects of physiotherapy during intermittent positive pressure ventilation. Anaesthesia 1972;27:258-64.

34 Holloway R, Adams EB, Desai SD, Thambiran AK. Effect of chest physiotherapy on blood gases of neonates treated by intermittent positive pressure respiration. Thorax 1969;24:421-6.

35 Fox WW, Schwartz JG, Schaffer TH. Pulmonary physiotherapy in neonates: physiologic changes and respiratory management. F Pediatr 1978;92:977-81.

36 Walsh CM, Bada HS, Korones SB, Carter MA, Wong SP, Arheart K. Controlled supplemental oxygenation during tracheobronchial hygiene. Nurs Res 1987;36:211-5.

\title{
Control of meningococcal disease
}

\section{Chemoprophylaxis for carriers and some contact groups}

Though small, the risk of meningococcal infection in household contacts of a patient with the disease is significantly greater in the general population. ${ }^{12}$ Two studies published this week (p 555 and p 569) confirm this, adding that, though the risk is greatest within the first few days after contact, ${ }^{3}$ it may persist for several months.

There are two possible chemoprophylactic strategies for managing this increased risk. Firstly, phenoxymethylpenicillin is offered to close contacts for seven days. A Norwegian study has shown that, though this regimen was protective for the duration of treatment, subsequent household cases occurred later, presumably because of a continued exposure to the carriers, who may have been the source of infection in the index case. ${ }^{+}$Secondly, the alternative strategy (which we recommend) is to try to eliminate the carriage of meningococci in the close contacts to reduce transmission to susceptible people..$^{5-7}$

Sulphonamides have been used to reduce transmission, but many of the strains producing disease in the United Kingdom are resistant, and consequently rifampicin is the best antibiotic to use (adults $600 \mathrm{mg}$ every 12 hours for two days; children aged over 1 year $10 \mathrm{mg} / \mathrm{kg}$ every 12 hours for two days; children below 1 year $5 \mathrm{mg} / \mathrm{kg}$ every 12 hours for two days). Ciprofloxacin as a single oral dose of $500 \mathrm{mg}$ is an alternative for adults but is not yet licensed in the United Kingdom for children and adolescents. Ceftriaxone in a single dose of $250 \mathrm{mg}$ intramuscularly is also effective and is not contraindicated in pregnancy. ${ }^{8}$
Rifampicin should be offered as soon as possible (and ideally simultaneously) to those living with the patient, to anybody who has kissed the patient in the 10 days before admission, and to convalescent patients before discharge from hospital. ${ }^{7}$ Contacts receiving rifampicin must be told about its side effects: discoloration of soft contact lenses; interaction with oral contraceptives; and colouring urine, saliva, and other body secretions orange red. These side eft :cts are not contraindications.

Bacterial resistance to rifampicin may emerge after chemoprophylaxis and, as found by Cooke et al, secondary cases may be due to meningococcal strains resistant to rifampicin. Hence the use of this antibiotic should be restricted to contact groups known to be at increased risk. Infection among hospital staff contacts of cases of meningococcal meningitis or septicaemia is rare, and such contacts are considered to be at increased risk and to require prophylaxis only if mouth to mouth contact has occurred. (The possible nosocomial spread from a patient with a respiratory tract infection reported by Eriksen and colleagues ( $p$ 568) arose out of an unusual set of circumstances.) School contacts do not require chemoprophylaxis unless more than one related case occurs in the school. Nevertheless, special circumstances may justify the wider use of chemoprophylaxis, such as the attendance of the index case in the 10 days before the onset of the illness at a party at which young children or teenagers are present or at a nursery school or day care centre, which may resemble a "household" setting. Taking swabs from the household and 
family contacts before offering chemoprophylaxis is unnecessary and does not contribute useful information; on the other hand, when clusters of cases occur, estimates of the prevalence of carriage of virulent strains may be required to help in developing a control strategy. Such incidents should be discussed with the Communicable Diseases Surveillance Centre (01 200 6868) or the Public Health Laboratory Service meningococcal reference laboratory, Manchester (061 445 2416) (or in Scotland the Communicable Diseases (Scotland) Unit or the meningococcal reference (Scotland) laboratory (041 9467129$)$ ).

If meningococcal infections are due to either group $\mathrm{A}$ or $\mathrm{C}$ organisms (but not group B) vaccinating the contacts may be considered for children in schools where more than one case has occurred and in households of cases where there are children or teenagers, given the prolonged increased risk of disease in household contacts. ${ }^{9}$ The use of vaccines should be discussed beforehand with the Communicable Diseases Surveillance Centre or Public Health Laboratory Service meningococcal reference laboratory, Manchester (or in Scotland the Communicable Diseases (Scotland) Unit or the meningococcal reference (Scotland) laboratory).

In controlling the disease in the community close communications must be maintained among clinicians, microbiologists, and public health doctors so that suspected cases are reported immediately by telephone and subsequently by formal notification. The community physician responsible for infection control should keep a register of all suspected cases of meningococcal disease, both as a record of actions taken and to facilitate early recognition of clusters of cases.

In the long term we hope that meningococcal disease will be controlled by developing vaccines that give prolonged protection against all groups of meningococci. Currently the first field trials of group B vaccines are in progress in Chile and Cuba.

Chairman, PHLS Meningococcal

D M JONES

Infections Working Party,

Public Health Laboratory,

Withington Hospital,

Manchester M20 8LR

1 Meningococcal Disease Surveillance Group. Analysis of endemic meningococcal disease by serogroup and evaluation of chemoprophylaxis. F Infect Dis 1976;134:201-4.

2 De Wals P, Hertoghe L, Bortee-Grimee I, et al. Meningococcal disease in Belgium, secondary attack rate among household day-care nursery and pre-elementary school contacts. I Infect 1981; 3(suppl 1):53-61.

3 Munford RS, Taunay AE, Morais JS, Fraser DW, Feldman RA. Spread of meningococcal infection within households. Lancet 1974; ii: 1275-8.

4 Hoiby EA, Moe PJ, Lystad A, Froholm LO, Bovre K. Phenoxymethyl-penicillin treatment of household contacts of meningococcal disease patients. Antonie Van Leeurwenhoek 1986;52:255-6. household contacts of meningococcal disease patients. Antonie Van Leeuwenhoek 1986;52

6 Wilson HD. Prophylaxis in bacterial meningitis. Arch Dis Child 1981;56:817-9.

6 Wilson HD. Prophylaxis in bacterial meningitis. Arch Dis Child 1981;56:817-9. Abramson JS, Spika JS. Persistence of Neisseria meningitidis in the upper respiratory tract after
intravenous antibiotic therapy for systemic meningococcal disease. F Infect Dis 1985;151:370-1. 8 Schwartz B, Al-Ruwais A, A'ashi Jalal, et al. Comparative efficacy of ceftriaxone and rifampicin in eradicating pharyngeal carriage of group A Neisseria meningitidis. Lancet 1988;i:1239-42.

9 McCormick JB, Bennett JV. Public health considerations in the management of meningococcal disease. Ann Intern Med 1975;83:883-6.

\section{Alcohol and the immune system}

\section{A causative agent in altering host defence mechanisms}

A 20 year old man with a drink problem became bedridden with pneumonia and severe peripheral neuropathy. Pneumocystis carinii and tubercle bacilli were isolated from his sputum, and it was thought that he might have AIDS. The results of a test for HIV were negative, however, and his condition gradually improved over many months with his abstention from alcohol.

Although the immune system may be suppressed in alcoholic liver damage ${ }^{1}$ or malnutrition, ${ }^{2}$ the possibility that excessive alcohol alone may damage the immune system has received less attention. ${ }^{34}$ Heavy intakes of alcohol may alter the production and turnover rates of lymphocytes in the thymus or spleen, or both, with a resultant shift in the relative concentrations of the lymphocyte subpopulations. ${ }^{5}$ These include B cells, which are precursors of the plasma cells that secrete specific antibody, and T cells, which mature under the influence of the thymus and are concerned with cell mediated immunity. Alcoholic subjects with leucopenia also have a low absolute lymphocyte count, which is reversed when they stop drinking. ${ }^{6}$ When compared with values in control subjects the circulating $\mathrm{T}$ lymphocyte counts are significantly reduced in alcoholic subjects, as is their ability to undergo blastic transformation on mitogenic stimulation. ${ }^{78}$ Furthermore, non-specific activation of $\mathrm{B}$ lymphocytes occurs in all patients who drink alcohol regularly in excess. ${ }^{9}$ In vitro alcohol alters both the development and the sensitivity of lymphocytes as a result of decreased natural killer cell activity, ${ }^{10}$ which is also depressed when assayed in the presence of alcohol. " $\beta$ Endorphins in the brain normally enhance killer cell activity but are reduced by the chronic abuse of alcohol, ${ }^{1213}$ and this may be a further cause of impaired immunity.
Prolonged drinking disturbs the reticuloendothelial system of the liver by interfering with the mobilisation and activation of macrophages and their phagocytic activity. ${ }^{14}$ In vitro alcohol impairs the chemotaxis and adherence of granulocytes to capillary walls. Impaired adherence might prevent diapedesis of granulocytes through the capillary walls to sites of injury, and locally impaired phagocytosis and intracellular killing of bacteria in lung tissue might partly account for lowered resistance to pulmonary infections among alcoholic subjects. ${ }^{15}$

Alcohol appreciably inhibits cell mediated immunity, and this may contribute to the high prevalence of tuberculosis among alcoholic subjects. ${ }^{16}$ Antiviral immunity requires natural killer cells and antibody directed cytotoxicity, ${ }^{17}$ both of which are suppressed by alcohol, so that alcoholic subjects may be at an increased risk of both hepatitis and HIV infection.

Other factors might also be concerned with altered immunity in alcoholism. Undernutrition, associated with a reduced intake of protein, vitamins, and sources of energy, may lead to an increased production of corticosteroids, which might then suppress cellular immune function. ${ }^{4}$ The synthesis of immunoglobulin $G$ by peripheral blood mononuclear cells in vitro and serum IgG concentrations in vivo are abnormal in alcoholic subjects, even when they have no clinical or biochemical features of liver damage. ${ }^{69}$ Raised concentrations of IgA might result from damage to the gastric and the intestinal mucosa leading to stimulation of the immune system. ${ }^{18}$ An outpouring of primed $\mathrm{T}$ helper cells or $B$ cells into the circulation, together with reduced phagocytic activity of the Kupffer cells, would result in an "antigenaemia," with a constant stimulation of the immune 